\title{
Dermatology Residency Training in COVID-19 Pandemic: Transition from Traditional to Online Teaching
}

\author{
Arfan ul Bari \\ Department of Dermatology, PNS Shifa Hospital, Bahria University Medical and Dental College, Karachi, Pakistan
}

\begin{abstract}
The novel coronavirus (COVID-19) pandemic has placed unprecedented demands on the health profession; and unique challenges are emerging in almost all fields of medicine, including dermatology. This ongoing health crisis has also significantly disrupted medical education globally. As the pandemic continues to develop, traditional medical education of in-person lectures, seminars and bedside teaching is being rapidly replaced by various modalities of online education. This transition was already taking place for last many years in the developed world, but developing countries were experiencing barriers even for its partial implementation. Current challenge of COVID-19 has created an opportunity for these countries to adopt online teaching as a major tool of education. We describe our preliminary experience of this rapid transition, its advantages, challenges faced and future perspectives in a resource-constrained environment and ongoing enormous health crisis of COVID-19.
\end{abstract}

Key Words: Novel coronavirus, Medical education, Developing countries, Postgraduate training, Online teaching, Elearning, WhatsApp, Pandemic pedagogy.

How to cite this article: Bari AU. Dermatology Residency Training in COVID-19 Pandemic: Transition from Traditional to Online Teaching. J Coll Physicians Surg Pak 2020; 30(JCPSPCR):CR63-CR66 https://doi.org/10.29271/jcpsp.2020.JCPSPCR.CR63.

Online teaching and learning is not a new phenomenon, but has been mainly used as a part of face-to-face teaching for the last many years in different parts of the world. ${ }^{1}$ In Pakistan, the culture of online teaching and distant learning is still developing. Recently, many medical colleges in Pakistan have shifted to some form of online teaching to cover up courses lagging behind due to COVID- 19 lockdown. Even many schools have started their online teaching programmes. The current COVID-19 pandemic challenge made us to adopt this mode of learning in our specialty of dermatology. ${ }^{2}$ Dermatology residents are neither involved in care for the acutely ill patients nor are at the frontline in the current COVD-19 pandemic. Therefore, presence of residents in hospital would not only expose them to risks of acquiring the virus but also increase the chances of spreading the virus when asymptomatic in the course of training. Moreover, with the outbreak of pandemic, the flow of routine patients to dermatology clinics suddenly slowed down; and dermatology services in most teaching institutions were closed.

Correspondence to: Dr. Arfan ul Bari, Department of Dermatology, PNS Shifa Hospital, DHA II, Karachi, Pakistan

E-mail: albariul@gmail.com

Received: May 25, 2020; Revised: June 18, 2020;

Accepted: June 18, 2020

DOI: https://doi.org/10.29271/jcpsp.2020.JCPSPCR.CR63
Thus, practically all the teaching and training activities of residents were suspended. The only solution to resume residency training in such a scenario was online teaching, using digital technology.

In medical education, there has been a rising trend of using social media and smart phones for teaching and learning. ${ }^{3}$ Facebook, WhatsApp, Instagram, YouTube, Zoom, and Google Classrooms are the major platforms being used for collaborative learning, improved communication and knowledge sharing. ${ }^{4}$

Our dermatology department is accredited for postgraduate training for the last many years; and currently, we have three supervisors and 28 residents. After knowing the fact that all residents had access to smart phones and internet, we thought of using the most widely used instant messaging app in the world "WhatsApp" for resumption of education in our setting. We are sharing our experience of its use in teaching and training specific to dermatology.

We initially planned resumption of clinical activities in hospital by dividing the batch into two groups. One group would attend the clinics with routine lectures, tutorials, journal clubs, and case presentations; while the other group would be staying at home, doing self-study and flipping the group after 2 weeks. But then realising the gravity of risk of exposure in hospital setting and deficiency of personal protective equipment (PPE), this idea was dropped. In mid-March 2020, residency training was completely suspended as trainees were directed by the administration to stay at home until further instructions. The faculty devised a provisional training plan by using WhatsApp 
platform in third week of March and started implementing it on monthly basis from the fourth week. The teaching methodology was self-study of allocated topics, followed by twice or thrice weekly assessment through multiple choice questions (MCQs) and short assay quesitons (SAQs). A WhatsApp group of all trainees and consultants ( 28 residents and three consultants) was created. With consultation of senior residents, we selected chapters and topics from Rook's textbook of dermatology, 9th edition, related continuing medical education (CME) and review articles from Journal of American Academy of Dermatology (JAAD). These topics were distributed to all residents. Easy topics were assigned to 1st year residents, moderately difficult to $2^{\text {nd }}$ year, and difficult and lengthy tasks were given to the 3 rd year residents. They were asked to prepare the given tasks thoroughly and construct 10 good quality MCQs and 2 SAQs out of the academic material assigned to them. All the residents already had the basic knowledge of constructing clinical scenario-based MCQs and SAQs, according to format of College of Physicians and Surgeons, Pakistan (CPSP). This method was selected considering the established role of MCQs and SAQs in knowledge application and higher cognitive skill assessment. ${ }^{5,6}$ The task of MCQs and SAQs development for a particular topic by each resident involved higher order cognitive involvement in understanding of the concerned topic and then further cognitive involvement of development of assessment questions. This was a crucial academic activity for improved learning and understanding of the topic. Within a week's time, we started getting responses from residents. These responses were initially evaluated by an individual supervisor and improved and modified after detailed discussion and validated collectively by all three supervisors. The importance of the content, concept, importance, difficulty and cognitive level of each MCQ and SAQ was taken into account. Simple recall questions were eliminated or modified into context-rich, clinical scenario-based and problem solving type to test the moderate to higher cognition skills. Around 30-50\% of questions were added by supervisors in each test. As we know that, "assessment drives learning", we scheduled online tests every Monday, Wednesday and Friday for designated topics (Table 1). Residents were instructed to be available online on these days from 1100 to $1200 \mathrm{hrs}$. We uploaded test questions (10 MCQs and 2 SAQs) in Microsoft (MS) Word file on WhatsApp group exactly at 1100 hrs. All the residents appeared in the test except the one who was involved in preparing it. Residents completed the test in one hour time and emailed their responses within 5 minutes to their colleague who did not appear in the test. Technical delay of 5-10 minutes was acceptable, but afterwards one mark penalty for each minute delay was imposed. In the meantime, supervisor responsible for conducting that very test shared the keys for the questions with the resident who then marked the responses accordingly. After marking, the responses were sent back to the supervisor for final compilation. After each test, residents were asked to give their feedback about quality of the assessment and difficulty of the questions.
During $1^{\text {st }}$ month ( $4^{\text {th }}$ week of March to 3 rd week of April), we successfully conducted nine routine tests and one grand test (comprising all mini tests). During $2^{\text {nd }}$ month (from $4^{\text {th }}$ week of April to $3^{\text {rd }}$ week of May), we scheduled tests on every Monday and Friday and have so far completed six tests. In this way, we were able to engage residents and ourselves actively in teaching and learning during the midst of this ongoing health crisis. During the previous two months, we have covered approximately $20 \%$ of the curriculum, which would have otherwise been learnt by the residents in 6 months (Tablel).

Table I: Details of curriculum covered in two months of online teaching.

\begin{tabular}{|l|l|l|}
\hline No & Date & Topics covered \\
\hline 1 & $31-03-2020$ & Morphoea and related disorders \\
\hline 2 & $02-04-2020$ & Sexually transmitted infections (Syphilis) \\
\hline 3 & $04-04-2020$ & Rheumatoid arthritis and related Disorders \\
\hline 4 & $06-04-2020$ & Systemic lupus erythematosis \\
\hline 5 & $08-04-2020$ & $\begin{array}{l}\text { Dermatomyositis + Antiphopholipid } \\
\text { antibody ayndrome }\end{array}$ \\
\hline 6 & $10-04-2020$ & $\begin{array}{l}\text { Systemic sclerosis + Moxed connective } \\
\text { tissue disease }\end{array}$ \\
\hline 7 & $13-04-2020$ & Grand test (including topics 1-6) \\
\hline 8 & $19-04-2020$ & Fungal infections \\
\hline 9 & $22-04-2020$ & Basal cell carcinoma, chemical peeling \\
\hline 10 & $24-04-2020$ & $\begin{array}{l}\text { Disorders of hypopigmentation and } \\
\text { depigmentation }\end{array}$ \\
\hline 11 & $30-04-2020$ & Purpura and vasculitic Disorders \\
\hline 12 & $04-05-2020$ & Porphyrias + Mucinosis + Amyloidosis \\
\hline 13 & $08-04-2020$ & Xanthomas + disorders of calcification \\
\hline 14 & $11-05-2020$ & Nutritional disorders + sarcoidosis \\
\hline 15 & $15-05-2020$ & Severe cutaneous drug reactions \\
\hline 16 & $18-05-2020$ & HIV + Kaposi's sarcoma \\
\hline 17 & $22-05-2020$ & $\begin{array}{l}\text { Squamous cell carcinoma + Merkel cell } \\
\text { carcinoma }\end{array}$ \\
\hline 18 & $30-05-2020$ & Grand test (including topics 8-17) \\
\hline
\end{tabular}

We have now planned to partially resume real-time patient-based learning in outdoor dermatology clinics. We have divided residents into 2 groups of 14 residents each. From $1^{\text {st }}$ June 2020, Group-A will attend clinics with all PPEs and appropriate social distancing. They will be involved in interactive teaching classes, tutorials, case presentations, journal club meetings for 2 consecutive weeks while Group-B will stay home and will be involved in self-study, dissertation writing and other medical writings. After 2 weeks, group-A will go in self-isolation at home and group-B will take over. This cycle will be repeated till resumption of normal academic activities at the institute. We also plan to do pairing in which one resident from group-A will pair with one resident of group -B to share learning with each other on daily basis. This will be monitored by one of the supervisors. In this way, we will be able to resume real-time patient-based learning and professional skills and competency enhancement, that we could not achieve in previous two months. This will be done with social distancing and changed outlook with PPE. We will also continue with written test on weekly basis (every Monday), where one group will take the test online and other will do it in classroom. 


\section{Advantages and challenges:}

COVID-19 has changed the landscape of education worldwide. The pedagogy being developed and followed during this health crisis has been named as "Pandemic pedagogy". ${ }^{7}$ While reflecting upon the pandemic pedagogy we applied in our set-up, we observed following advantages and disadvantages:

1. We were able to engage residents in academics without losing much time.

2. Residents were able to cover significant portion of their curriculum (Table I).

3. Significant improvement in cognitive skills in addition to clinical knowledge were expected through standardized assessments.

4. Empowerment of residents through active involvement in constructing the questions, conducting the test and at the same time evaluating their peers.

5. The reflective feedback from the residents revealed that they found the experience of being examiner/ evaluator as exciting for the residents. At the same time, they also realized the challenges of being a good examiner and evaluator.

6. No major logistics were required and it was economically feasible for residents, supervisors and the institution.

7. No technology-related barriers were faced as all the residents were already familiar and comfortable with the use of smart phone and WhatsApp.

8. The formative assessment by the supervisors on residents' performance helped identify areas for improvement and clarification of concepts.

9. It proved to be a productive academic activity for all the stakeholders involved (for trainees as their learning continued, for supervisors as fulfillment of their ethical and professional duty and for institution/licensing bodies for not having any brake in the training).

Following are the challenges wefaced:

1. This whole exercise was focused on cognitive learning skills only and lacked opportunities for learning of psychomotor and affective domains.

2. There was no opportunity for real-time patient-based learn-ing.

3. No hands-on training for procedural skills could be offered.

4. There could have been a possible element of dishonesty/cheating during online assessment.

5. During this academic activity, the residents had no exposure to manage acute dermatological emergencies.

6. There was lack of opportunity to explore cutaneous manifestations in COVID-19 positive cases in realtime and in detail.

7. Testing knowledge and cognitive skills through a selected clinical topic was likely to affect reliability as the diagnosis of clinical scenario in most cases already narrowed and resident could reach it without using higher levels of cognition.

We tried to improve content validity of the questions by asking more about differential diagnosis, solution of tricky clinical problems and advanced management plans of the given clinical scenarios.

We hope to amicably address most of the above-mentioned disadvantages by following our proposed training plan for coming months by adding pictures and videos to the learning content and make it more interactive. We also plan to incorporate online interactive lectures through zoom meetings and incorporate real-time MCQs solving using pollev.com. We plan to encourage our residents to take the free available online tutorials of different dermatological conditions in a structured way.

We have tried to transform our pedagogy according to the need of hour and we invite our colleagues involved in postgraduate training to share their experiences of teaching and learning in order to learn from each other's unique experience. We also look forward to having critical opinion and suggestions from our peers in this regard, so that we can adopt a better and more robust approach towards residency training of our postgraduate trainees in this transition phase of medical education that can go a long way in improving online education. A myriad of advantages can easily outweigh few inherent disadvantages. Moreover, the challenges can appropriately be addressed through little modifications and correction in applied pedagogy.

During COVID-19 pandemic and similar global health crises, online teaching and learning is an appropriate, cost-effective and feasible alternate to traditional medical education. WhatsApp, being a globally available free application in smart phones can be used effectively in knowledge sharing, cognitive skill enhancement and as an assessment tool even in resource-constraint settings.

\section{CONFLICT OF INTEREST:}

Author declared no conflict of interest.

\section{AUTHOR'S CONTRIBUTION:}

AUB: Contributed in all stages of conceptulization, gathering and recording data, writing and revising manuscript.

\section{REFERENCES}

1. Khan RA, Jawaid M. Technology enhanced assessment (TEA) in COVID 19 pandemic. Pak J Med Sci 2020; 36 (COVID 19-S4):S108-S110.

2. Rose S. Medical student education in the time of COVID-19. 
JAMA 2020;

3. Clavier T, Ramen J, Dureuil B, Veber B, Hanouz JL, Dupont $\mathrm{H}$, et al. Use of the smartphone app whatsapp as an elearning method for medical residents: Multicenter controlled randomised trial. JMIR Mhealth Uhealth 2019; 7(4):e12825.

4. Latif MZ, Hussain I, Saeed R, Qureshi MA, Maqsood U. Use of smart phones and social media in medical education: Trends, advantages, challenges and barriers. Acta Inform Med 2019; 27(2):133-8.
5. Ludley A. Context-rich short answer questions (CR-SAQs) in assessment for learning in undergraduate medical education. Med Educ Online. 2019; 24(1):1674569.

6. Amini N, Michoux N, Warnier L, Malcourant E, Coche E, Vande Berg B. Inclusion of MCQs written by radiology residents in their annual evaluation: Innovative method to enhance resident's empowerment? Insights Imaging 2020; 11(1):8.

7. Finn GM, Brown MEL, Laughey W, Dueñas A. Pandemic pedagogy: Using twitter for knowledge exchange. Med Educ 2020; 10.1111/medu.14242. 